\title{
The nature of Quality of Life: A conceptual model to inform assessment
}

DOI:

10.1111/jppi.12225

\section{Document Version}

Accepted author manuscript

Link to publication record in Manchester Research Explorer

\section{Citation for published version (APA):}

Alborz, A. (2017). The nature of Quality of Life: A conceptual model to inform assessment. Journal of Policy and Practice in Intellectual Disabilities, 14(1), 15-30. https://doi.org/10.1111/jppi.12225

\section{Published in:}

Journal of Policy and Practice in Intellectual Disabilities

\section{Citing this paper}

Please note that where the full-text provided on Manchester Research Explorer is the Author Accepted Manuscript or Proof version this may differ from the final Published version. If citing, it is advised that you check and use the publisher's definitive version.

\section{General rights}

Copyright and moral rights for the publications made accessible in the Research Explorer are retained by the authors and/or other copyright owners and it is a condition of accessing publications that users recognise and abide by the legal requirements associated with these rights.

\section{Takedown policy}

If you believe that this document breaches copyright please refer to the University of Manchester's Takedown Procedures [http://man.ac.uk/04Y6Bo] or contact uml.scholarlycommunications@manchester.ac.uk providing relevant details, so we can investigate your claim.

\section{OPEN ACCESS}


Title Page

Title : The nature of Quality of Life: A conceptual model to inform assessment.

Short title: The nature of QoL

Keywords: intellectual disabilities; quality of life; hierarchy of needs; capability approach; selfdetermination

Author: Alison Alborz, University of Manchester, Manchester, UK

\section{Correspondence:}

Manchester Institute of Education,

University of Manchester,

Oxford Road,

Manchester M13 9PL

Tel: $+44(0) 1612753342$

Email: Alison.alborz@manchester.ac.uk 
The nature of Quality of Life: A conceptual model to inform assessment.

\begin{abstract}
:
Issues: The phenomenon of quality of life (QoL) has been subject to ongoing debate and many models have been proposed. Over the latter half of the $20^{\text {th }}$ century QoL models have proliferated, particularly in relation to the population with intellectual disabilities (ID) which have arguably improved living conditions and helped to guard against abuse. While this is a complex phenomenon, there is agreement across a wide literature that QoL has two distinct aspects relating to the individual (whether disabled or not) and the resources necessary for a 'good' QoL. Considerable support is also provided for a number of diverse but robust domains. However, how the 'nature' of Qol is conceptualised is unclear.
\end{abstract}

Positions: The article reviews multi-disciplinary research on QoL and goes on to present a theoretical model of the nature of QoL that encompasses identified domains. The model is based on Maslow's hierarchy of needs (1987) which defines its scope; Sen's Capability Approach (1985), which elaborates the resource context impacting QoL; and Ryan and Deci's Self-Determination Theory (2000), which describe person-context interactions important to personally valued QoL. This conceptualisation was framed within four facets - Foundational wellbeing; Psychosocial wellbeing; Status; and Autonomy each of which have two aspects 'individual', describing personal needs that, when fulfilled, are associated with better quality of life, and 'context', describing resources necessary to enable individual need fulfilment.

Conclusions: The proposed QoL model demonstrates an intellectually lucid structure supported by literature. It does not attempt a definitive specification of all QoL constituents, but proposes delineation must be determined within the particular circumstances of a proposed assessment. Once determined, an exploratory approach to assessment is proposed. It is suggested this model represents a useful 'atlas' on the nature of QoL to guide development of assessments aiming to inform service developments or interventions. 
Keywords: intellectual disabilities; quality of life; hierarchy of needs; capability approach; self-

determination

\section{Introduction}

The term 'quality of life' (QoL) is so widely used as to have arguably lost any meaningful value. As much as a 'good' QoL is aspired to, and a topic of serious study within the social sciences, the term is also clearly used and abused within marketing or political campaigns in efforts to persuade. On one hand a political party will portray itself as the true champion of the nation and clear in its vision of how the population is to achieve the 'good life'. While on the other, commercial interests suggest that no one has the ultimate in QoL without a particular car, sofa, or soft drink. Alongside such pronouncements, the term is used more functionally and expressed through statistics describing national progress towards (un)specified goals representing citizens' QoL. So what are we actually referring to when we use the term?

It is generally recognised, that the field of 'QoL' is highly complex. It is not possible to access the full range of literature on the topic, particularly within the confines of a single article. However within these limits, development of QoL models will be briefly examined, alongside psychological and sociological understandings of its character and influences. A model using the work of Abraham Maslow on motivation and personality (Maslow, 1987), will be proposed. This framework comprises 'facets' of QoL within which individual and contextual aspects influencing QoL will be outlined, drawing on the work of Amartya Sen (1985). The place of the person within the model will be discussed, reflecting on theories of self-determination (Deci and Ryan, 1985; Ryan and Deci, 2000).

In conceptualising individual QoL, there appears no sound argument for defining different theoretical models for different populations. People with intellectual disabilities (ID), for instance, should be entitled to expect a valued QoL of the same scope as any other member of society. What will occasion particular consideration for this population is the impact of their disability across different aspects of their life and availability of concomitant contextual resources. Similarly, a QoL conceptualisation should 
apply across the full age range from babies and small children, to older people and frail elderly. In this case, developmental stage will influence QoL such that different elements may have greater or less salience at different life stages. However, the underlying concept should arguably remain constant. The model outlined here therefore is not targeted on 'adults' or people with ID but on 'people' in general.

The very wide literature on the topic clearly demonstrates that conceptualisation of QoL must be a multi-disciplinary effort. This is appropriate as interest in factors impacting human existence and experience extend through multiple and overlapping lay, academic and professional spheres. Of all literatures, that relating to people with Intellectual Disabilities appears among the most multidisciplinary in character. It has been prompted, however, by real concerns over discrimination against, and poor treatment of this population, and a desire to improve the life experience of this group. Unsurprisingly, therefore, in recent years this sphere has made considerable progress into 'what' characterises individual ' $Q o_{L}$ ', while earlier researchers investigated the nature of QoL itself. Hence this is an important literature informing the conceptualisation presented here.

The author's background is in intellectual disability research, but using a psychological lens prompting particular concern with 'QoL' as experienced by individuals. While psychology has a long tradition of positivism, the author adopts a critical realist world view in which the existence of an underlying reality, or 'truth' is recognised, but it is acknowledged that our attempts to know and understand that reality is constructed from the labels we bestow derived from our own perceptions and experience. As such, these understandings are open to further investigation, discovery and change (Bryman, 2012). From this viewpoint, arguably, the 'true' QoL of an individual can only be ascertained by the person concerned, because only they, with their multitudinous characteristics, experiences, and ambitions, can make such a personal judgement. However, in terms of facilitating attainment of a personally defined 'good' QoL, local and national governments require evidence on which to base their policy decisions, to the benefit of their citizens and nation. They are responsible for provision of a fertile, resource and opportunity rich environment within which individuals have opportunities to achieve a 'good' QoL. It would be counterproductive, therefore, to present an entirely 'psychological take' on this topic. Instead, concepts 
and constructs from the wider, as well as individual-focused literatures on QoL will be synthesised. However, as a first step, clarification of how the 'human individual' is conceived within this article is required.

Human beings are complex; they are greater than the sum of their bio-psycho-social attributes. In this article, it is suggested that the 'human individual' is characterised by bio-psycho determinants that are unique to them, but that the interaction between these and their social environment determines their cultural growth and values as a member of a particular 'society'. Further, their perceptions, priorities and potential is, in turn, also influenced and impacted by the non-human environment. This composition of self - society - place is proposed to determine individuals' perceptions, thoughts and preferences regarding their life choices and ultimately their 'QoL'. A valued, 'good' QoL is therefore manifest by an individual's positive ratings (consciously or unconsciously) of themself, their relationships with other people, and their wider environmental context.

Do we need a new model of Quality of Life?

This article was prompted by recognition that promotion of QoL for individuals requires a clear conceptualisation of its nature. There have been many discussions and proposed models of QoL, with considerable effort on conceptualisation being spent over the past twenty to thirty years on devising measures that might be used to support improvements in people's lives. However there was little focus on theory to illuminate how decisions on 'what' to measure had been made. It appears timely, therefore, to review developments in QoL from a number of disciplines. In gaining an understanding of these perspectives, the need for a new theoretical model of QoL arguably becomes clearer.

\section{Part 1 - Background}

\section{The Development of QoL Models}

The literature illustrates that measurement of QoL has been pursued in the context of individuals, communities and / or nations (eg Brown, Hatton and Emerson, 2013; Brauer and Dymitrow, 2014; Diener, 1995). While conjecture on the nature of QoL has been a subject from the time of Aristotle, 
debate in the $20^{\text {th }}$ century began to feed into national agendas and policy. Models of QoL were proposed from a range of disciplines, with some of the most active researchers being concerned with social policy. Below, key developments are reviewed that are representative of a wide ranging research activity on the topic.

Andrews and Withey (1976) noted the emergence of the term 'quality of life' at a time in the 1960s when it became apparent that indicators were signalling improvement in living conditions, but certain populations were manifesting discontent. Building on existing work on 'social indicators', concerned with economic and social measurement of national progress, they promoted consideration of subjective judgements alongside objective measurement, which they saw as interrelated. They identified 'life concerns' derived from research into issues people considered of significant concern to them, and used this knowledge to develop 'Social Indicators of Wellbeing'. These included both global (How do you feel about your life as a whole?) and specific indicators (housing, employment and family life) to provide general evaluations of 'life concerns' (Andrews and Withey, 1976). They suggested there should be no limit to the number of 'sets' of indicators that could be established.

QoL was therefore represented both by a comprehensive system of indicators, designed to encompass main aspects of the phenomenon, and by a global indicator thought to reveal its general character. Kuiranov (1980) argued comprehensive systems recognise the complexity of QoL but ultimately must be reduced to a 'functional mainstay' to represent it, and that this is difficult to detail. Accordingly, Kuiranov (1980) argued for a single concept of QoL and hence single 'integral indicator', but did not elaborate this 'concept'. His own solution focused solely on contentment with working life. His fundamental argument was that while a 'simple' solution is limited, it is attractive because of the difficulties in adequately outlining a comprehensive model of QoL. However, this type of single generic measure appears satisfactory only if our solitary goal is to establish whether people feel their lives are OK, or better than they were. This may be sufficient where our concern is national trends, but would not enable us to identify where a person, or their community / environment, needs support or intervention to improve their subjective and/or objective QoL. 
Acknowledging the importance of the subjective view, 'psychological indicators' were routinely employed in models of QoL. Identified life domains, associated with 'psychological wellbeing', included physical and material wellbeing; relations with other people; social, community, and civic activities; personal development and fulfilment; and recreation (Flanagan, 1982). 'Satisfaction with life' domains included marriage and family life, health, standard of living, and amount of education (Campbell, Converse and Rodgers 1976). However, it was recognised that assessment of perceptions may represent what the person thought the researcher wanted to hear, and that while 'satisfied' the person's external reality might be unacceptable from an objective QoL perspective and so this must still be accounted for (Zautra and Goodhart, 1979).

The 'goodness-of-fit', or social policy approach within the ID research community, attempted to address this issue by identifying unmet needs, which were then weighted by importance and allocated resources on this basis. This type of QoL assessment compared the person's needs with their environmental resources, to determine the gap between them. 'Higher' QoL was represented by a good fit between needs and resources (Murrell and Norris, 1983, cited by Day and Jankey, 1996).

The social policy approach to QoL was also adopted as a way to implement policy aspirations in practice. These models focused on outcomes associated with 'community adaptation' thought to represent a better QoL (Schalock, 1990). Here, domains related to social policy goals on Independence (living environment), Interpersonal and community relationships, and Productivity. Schalock and Thornton (1988) proposed a model directly reflecting this agenda. Where levels of the model reflected goals of Independence, Productivity, or Community integration linked to 'Home', 'Job' and 'Community (recreation/leisure)' contexts (Schalock, 1990, Fig 14.1, p146). Focus on these target variables aimed to yield person centred outcomes in each context, and were proposed to represent enhanced (or opportunities to enhance) QoL.

Social policy also drove Goode's (1990) development of a 'Client-Driven, Ecological, QOL Model'. This model put the perception of the individual at its core. That is, a need/ environmental resource contrast was made alongside contrasts between a person's abilities and perceived environmental demands upon 
them. The interactions between these elements, and additional external elements (impacting the person's perceptions) and life events out of the person's control, were taken into account. These were thought to impact 'life setting' satisfaction level and thereby their overall QoL. Goode (1990) stated that where these are satisfactory to both the person with disability and significant others in the setting, then this is conducive to experiencing a better QoL. As with the Schalock and Thornton (1988) model, the social policy remit meant this model was devised with people with disabilities in mind and not all 'human individuals'. Goode's model's 'setting related' view of QoL arguably limits its scope further. While it may be pertinent to address specific setting related QoL issues for a person, it is suggested here that this needs to be explored within a holistic concept of what comprises QoL. Tying QoL to policy goals arguably narrows the aspiration of the concept.

Ethnographer Robert Edgerton (1990) criticised the proclivities of social scientists towards compiling sets of standards and creating 'simple' measures to establish a person's current status. While acknowledging these may help guard against abuse and neglect of people with ID, he was uncomfortable that individual choice might be replaced with a "QoL Quotient". He suggested establishing domains of QoL, to be reached to acceptable standards, may be a 'harmless' expression of values, but could 'create frustratingly unattainable expectations' (Edgerton, 1990, p150). This is a serious point. It would not profit anyone to add to the daily trials and anxieties of individuals with ID. However, how do such sentiments sit alongside a person's right to 'aspire', to have dreams of 'what might be'?

Edgerton champions individual choice and the notion that people with ID should determine the life they wish to lead. In reflection on his own, and others' longitudinal research on 'life satisfaction' he noted some individuals retain a positive and optimistic outlook despite life events that may trouble them greatly for a time. Similarly he noted those tending to a negative and pessimistic outlook remained pessimistic despite the short term impact of positive life events. Edgerton (1990) commented that this appeared to relate to their 'internal dispositions' ( $\mathrm{p} 156)$ and was not an ongoing reaction to environmental factors. He concluded that a person's subjective sense of wellbeing may derive more 
from internal characteristics such as personality or temperament than from features of their environment, but supported the notion that 'wellbeing' is setting-specific, such that occupational 'wellbeing' can be different to residential 'wellbeing'.

The early social indicator QoL model literature reflects a great deal of work on addressing concerns voiced by the population but does not establish an underlying QoL concept. Social policy approaches appear limited in scope, or too context specific. There the ambition appeared to be assessment of social policy goals rather than providing conceptualisation of QoL to support a range of uses. However, important individual perspectives on QoL were accessed alongside objective measurements.

Longitudinal ethnographic work advised caution in indiscriminate application of 'standardised values' to people with ID and suggested that an individual's personal characteristics seemed to have a significant impact on how they evaluated their QoL.

The issue of subjective evaluation in assessment has been subject to criticism. Day and Jankey (1996) noted measurement of subjective elements of QoL were often on researcher imposed domains and risked omitting elements important to the individual. Consequently, they suggested that the person should define the terms by which their lives should be evaluated, and should conduct that evaluation. However, investigation of this approach by Day, Jankey, Alon, Clingbine and Reznick (1993, cited by Day and Jankey, 1996) found that even within one subgroup of participants (people with disabilities, chronic health problems, or no problems), definitions of QoL were very different. Further, no between group comparisons could be made. In response a simple 'overarching model' of higher order factors was established describing 'how' evaluation of QoL was achieved rather than 'what' QoL looked like for individuals or groups (Day and Jankey, 1996, p47-49).

Building on earlier models of QoL and associated ID literature, Renwick and Brown (1996) proposed a model recognising that people have physical, psychological and spiritual dimensions, and an innate need to 'belong' to communities in physical and social senses. They also suggested individuals need to pursue their own goals, and make their own decisions and choices as unique human beings. This was a significant move towards a more holistic conceptualisation of the nature of life quality. 
Renwick and Brown's (1996) ‘Centre for Health Promotion'(CHP) model of QoL was conceived as equally applicable to people with and without disabilities; as multidimensional, dynamic and evolving; and arising from ongoing interaction with the environment. While they viewed the perspective of the person as most important in understanding their QoL they noted the 'macro environment', in which opportunities and constraints to choice operate, is also influential but that the importance the person attaches to each affects its impact.

The CHP QoL Model included three major components, Being, Belonging and Becoming. 'Being' comprised physical health status (e.g. health, nutrition and fitness), psychological wellbeing (e.g. feelings and self-evaluations such as self-confidence)and spiritual beliefs and values (e.g. religiosity or intangible experiences related to music or other arts); 'Belonging' comprised physical environment context (e.g. privacy and safety), social environment (e.g. meaningful relationships with family and social contacts) and community resources (e.g. access to employment, education and other services); and 'Becoming' comprised practical activities (e.g. studying, housework and self-care), leisure activities (to promote relaxation, or work-life balance), and growth activities promoting development of skills and knowledge formally or informally.

Renwick and Brown (1996) proposed that importance and enjoyment of aspects of QoL are determinants moderated (increased or decreased) by control (ie perception of the degree of control over important possibilities); and potential opportunities (perceptions of potential - current and likely opportunities). The model recognised the need to consider wider contextual factors alongside the individual's wellbeing needs. While contextual and individual factors are included within the three components (Being Belonging Becoming) of the CHP QoL Model, the individual/context interrelationship arguably requires further elaboration and explanation. Moreover, Day and Jankey's (1996) conclusion, that factors of importance to individuals need to inform QoL definition (Day et al, 1983), needs to be addressed. The Day and Jankey (1996) proposal, however, does not clarify whether individuals were guided in their consideration of possible dimensions of QoL that 'might' be reflected upon in deciding 'what' is important. 


\section{Psychological influences on QoL evaluation}

Edgerton's ethnographic work pointed to issues of 'temperament' that may impact on personal evaluation of QoL and, indeed, psychologists have also been concerned to establish personal factors that characterise, or impact, QoL. Much of this work refers to 'subjective wellbeing', clearly taking a person-centric view of QoL and arguably lacking attention to wider context. Stones and Shye (2014) present strong evidence in support of the fundamental role of individual characteristics in perceptions of QoL, or 'Subjective Wellbeing' (SWB). Evidence from twin studies comparing SWB assessment scores against other measures, for pairs of monozygotic (identical) and dizygotic (non-identical) twins, revealed a strong relationship between genetic make-up and SWB scores (e.g. Stones, Kozma, McNeil and Worobtz, 2011). This, and other evidence strongly suggested a genetic component that mediates some aspects of QoL/SWB (e.g. Schnittker, 2008). For example, genetic influence was demonstrated to relate more clearly to tendency to evaluate life issues in particular ways over the long term, rather than in the short term or for specific events (Diener, Suh, Lucas and Smith, 1999). There is also general agreement that a genetic component underlies individual personality traits, and these impact perceptions of, hence differences in SWB/QoL (Weiss, Bates and Luciano, 2008; Schnittker, 2008).

Temperament, is an 'umbrella' term reflecting a number of innate aspects of personality, such as extraversion (Stones and Shye, 2014). It develops in response to these internal characteristics and socialisation, and is associated with 'disposition' (tendency to act in particular ways). Both temperament and disposition have been used as explanatory factors for perceived QoL. As noted above, for example, Edgerton's (1990) longitudinal research indicated that some individuals would 'bounce back' from adverse events after a period of time, to assume their usual sense of possessing a good QoL, while good fortune did not permanently reverse sense of poor QoL for others (e.g. Ormel, 1983). Differences in temperament are said to account for differences in perceptions of QoL between people in similar contexts.

'Personality' (including temperament), has been defined as comprising the 'more or less stable, internal factors that make one person's behaviour consistent from one time to another, and different from the 
behaviour other people would manifest in comparable situations.' (Child, 1968, p83, cited by Eysenck, 2000 p 744). Weiss, Bates, and Luciano (2008), among others, have noted a 'general factor of personality' that reflected differences in scores on a life satisfaction scale (Musek, 2007). They report 'evaluative cognitions' (processes involved in subjective evaluation) research suggests that different measures of wellbeing, regardless of content, tend to 'co-vary'. That is, a person who scores highly on one measure will also tend to have high scores on other measures of wellbeing.

The literature discussed above suggests that despite changes in the way we act or experience life, there is some consistent thread of 'self' running throughout. This notion reflects Antonovsky's (1987) concept 'Sense of Coherence' (SoC), said to be key to the theory of salutogenesis (meaning origins of health) (Langeland, 2014). SoC is said to be a dynamic, enduring and pervasive confidence of the part of the individual that their internal and external environments in life are comprehensible (ie structured, predictable and explicable), manageable (ie they have resources to meet 'environmental' demands), and meaningful (ie they are of interest to the person and are worth engaging in), (Antonovsky, 1987). Resonant with the CHP QoL model (Renwick and Brown, 1996), individuals are characterised as biopsychosocial beings who are also spiritual. They are seen as actively involved in seeking health and 'self-actualisation', through being proactive and reactive, and making choices to determine their own path - a factor highlighted by Bach and Rioux (1996). Antonovsky (1987) saw SoC as a stable attribute once a person reaches maturity. However it is now suggested that SoC may be improved through appropriate interventions (Langeland, 2014).

Related to this notion that personality/temperament is 'more or less stable' are a series of studies that have suggested changes in conditions can cause temporary changes in perceived QoL/SWB but that persons adapt (habituate) to the change and ultimately revert to their constitutional disposition ('Set Point Theory', Lykken and Tellegen, 1996). This was confirmed by Easterlin (1974, cited by Headey, 2014 ) in relation to the economic domain of life, where greater wealth provided only temporary improvements in SWB. However, some fundamental life events, or changes in family circumstance or health, do appear to cause permanent changes in SWB (Easterlin, 2005). Headey (2014) concludes that 
individual and contextual factors both account for differences in SWB. He argued that individual factors, out of the person's control (e.g. personality traits and genes), may account for the relative stability seen in SWB ratings, while contextual factors such as objective conditions, and individuals' preferences and choices influenced by mood, may account for short term changes in SWB.

Day and Jankey's (1996) review of psychological literature also demonstrated links between QoL and self-esteem, optimism, sociability and sense of coherence (Kozma and Stones, 1978; Scheier and Carver, 1985; Emmons and Diener, 1985; Jankey, 1992 respectively, all cited by Day and Jankey, 1996). However, they noted a dearth of qualitative studies to explain the meanings behind satisfaction ratings, and variations in mood and other factors, that impact quantitative measures.

These literatures lend support to the notion of a psychological/individualistic aspect that must be accounted for in elaborating a model of QoL. Research on psychological and physical factors that influence subjective wellbeing, and/or its evaluation has produced strong evidence that individual characteristics account for different evaluations of wellbeing in similar circumstances, and that a personally constructed model of QoL is 'idiosyncratic'. Overall, psychological and social science accounts appear congruent, though they emphasise different but related aspects of QoL. The difficulty arises in attempts to draft an 'exact' specification for a 'definitive' model (Kuiranov, 1980).

\section{The place of 'the person' within QoL Models}

The discussion above illustrates that characteristics of the individual are highly likely to influence their subjective evaluation of their QoL. The place of the person, therefore, within any QoL model is significant but often only referred to obliquely. Pertinent here are issues of choice and control, and the higher order factor self-determination, which are referred to in the QoL literature. Bach and Rioux (1996) discuss the importance of 'self-determination', not to determine the character of QoL evaluation for individuals as Day and Jankey (1996) had proposed, but for personal goal setting. Wehmeyer and Abery (2013) have emphasised the importance of self-determination in enabling people with ID to achieve a valued QoL. For example, Wehmeyer and Schwartz (1998) found higher ratings of self- 
determination were associated with better ratings of QoL among adults with ID. They found QoL ratings negatively impacted where choice and control restrictions were imposed in settings. Bach and Rioux (1996) agree self-determination is achieved in the context of 'freedom from' constraints imposed by others, but also 'freedom to' follow their needs or aspirations. They argue that governments have a role in restricting freedoms, where this is legitimate, but also to provide the conditions necessary for individuals to act on their freedom to pursue needs or aspirations. This has implications for states which may need to enact laws (such as the UK Equality Act 2010) to remove barriers to participation in, or use of community or national facilities or resources, and so is an important contextual element of any QoL model.

Michalos (2014) extended this analysis of the 'place of the person', pointing out that QoL is not only defined by what the person thinks and feels about their circumstances, but what they do about that evaluation, and the consequences of those actions. That is, a person's perceptions can impact both their own and other's living conditions and thus they are not passive subjects within a QoL model. Michalos (2014) proposed four potential subjective QoL assessment outcomes, including correctly perceived good or bad conditions (Real Paradise and Real Hell), and 'false positive' and 'false negative' perceptions that incorrectly evaluate good or bad conditions (Fool's Paradise and Fool's Hell). Consequently, he argued while it is appropriate that an individual's evaluation of their QoL should take precedence, it should not override all other factors. He proposed a 'good life' must include personal satisfaction but should be based on conditions that are clearly considered 'good' (based on objective, effective measurement) by all reasonable people. Where the objective measure suggests poor conditions but individuals evaluate their situation as 'good', due to mental incapacity of any character, then 'we are reasonably warranted in over-riding their judgments' (p5308), provided 'we' are in agreement on this issue.

In the ID QoL literature, therefore, this objective/subjective assessment dualism is presented as fundamental and dynamic in nature. However the issue of the extent to which we are justified in imposing our view of QoL domains, or whether personal choice is discounted for a person who, in 
Michalos' terms, appears to be in Fool's Paradise, is debatable. Certainly, Edgerton (1990) was opposed to over-riding the views of individuals with ID. He considered there is a duty to ensure access to good housing, healthcare, recreational activities and so on, but that:

$\therefore$ we must assure that it is persons with mental retardation (sic) who choose what they want, not we who choose for them. And if their choices do not invariably bring them a greater sense of well-being, we should not then impose our choice on them. They, like the rest of us, should have the right to strive for satisfaction in life in their own way. And we must understand that some of them, like the rest of us, will be more successful than others.' (Edgerton, 1990, p158)

Edgerton's view emphasises choice and control but presupposes that persons with ID will have mental capacity to choose from among options. The case is less clear cut where an individual has severe or profound ID. Nevertheless, the point is well made that we should not impose standards on others. For example there may be situations where we ourselves might reject the generally accepted 'good' life choice, knowing full well the objective reality of the situation, because we want something different for ourselves. This supports that the view that individual choice should not be over-ridden unless there are clear risks to health or survival, and the person demonstrably does not have the mental capacity to make, or comprehend the potential or actual severe consequences of a choice (in the UK this is enshrined in the Mental Capacity Act 2005). The place of the person in the model is therefore an important consideration in the development of a conceptualisation of QoL.

So what does psychological theory add to this discussion? It suggests that personal characteristics influence whether different people perceive the same life circumstances as contributing to a 'good' QoL. It suggests that any assessment of QoL may only provide a 'snapshot' of a person's view of their life situation at that moment because of the passing impact of short term events and enduring impact of underlying disposition or temperament. To obtain a representative evaluation, therefore, it may be necessary to undertake a series of assessments to establish a consistent profile of an individual's QoL. In terms of development of interventions, support services or opportunities to achieve valued life goals, some understanding of individual difference appears warranted to enable a proactive, rather than reactive, approach that facilitates a person-driven, (and avoids a wholly researcher/service provider driven) agenda for assessing QoL that recognises the place of the person at its centre. 


\section{Part 2 - Model Derivation}

\section{The proposed model of QoL}

The sections above outline the history of progress towards development of a QoL model, and some of the wider psychological literature addressing key factors relating to individuals that require consideration in a QoL assessment. Below a model of QoL is proposed that aims to bring significant theoretical literature together to inform a model representing the 'nature' of QoL that may be used to guide such assessments.

Four major literatures underpin the model presented here, principally that of Maslow (1987) on Personality and Motivation (representing influence of individual characteristics); but also the economic orientated theory (representing contextual influences) postulated by Sen (1985) and colleagues on the Capability Approach; Self-Determination Theory (representing the place of the person in the model) proposed by Deci and Ryan (1985); and contemporary QoL research (representing agreed domains important to QoL) within the ID field (e.g. Cummins, 2005; Schalock and Verdugo 2002; Renwick and Brown, 1996) .

\section{QoL and Maslow's Theory of motivation and personality (1970; 1987).}

Maslow began working in the field of 'Motivation and Personality' in the mid-1950s, and honed his theory over the following 15 years to establish the 'Hierarchy of Needs' (HoN) we know today (Maslow, 1970, 1987). While Maslow himself did not refer to his work in terms of QoL it is evident that in 'fulfilling' the individual 'needs' identified, the person would gain an improvement in their life quality.

In this work Maslow related 'motivations', which drive individuals to act, to personality. In describing the motivating prompts, he organised them within a hierarchical structure. Maslow (1987) proposed six levels to what he calls a 'positive theory of motivation', in a determined move away from the predominant deficit models of human experience and psychology common in the first half of the $20^{\text {th }}$ century. He suggested the more basic, or fundamental a need was considered, the more likely it was to be addressed by undertaking the actions required to fulfil it. In other terms, an individual's actions are 
prompted by the circumstances the person finds themself in. Maslow (1987) described human needs within this hierarchy, starting with the most fundamental and concluding with the 'highest', summarised here as follows:

1. Physiological - including very basic bodily functions necessary for life, (for example the need for oxygen); and 'non-homeostatic' needs for sleep, activity, sex, 'maternal behaviour' and so on.

2. Safety - including security and stability; protection from harm; freedom from anxiety, fear and chaos; structure / law and order.

3. Belongingness and Love - including giving and receiving affection; friends, a mate, children; roots, a neighbourhood, clan, or other grouping such as work colleagues.

4. Esteem - including a stable form of high evaluation of self; self respect; esteem from others (reputation or prestige).

5. Self actualisation - including engagement in activities that use personal talents (such as for music, athletics, invention, or parenting); to achieve concomitantly with aspirations.

6. 'Aesthetic' needs - including craving/preference for symmetry, closure, completion of the act, system and/or structure primarily in the (built) environment. This last 'need' does not feature strongly in his discussion of the model.

While Maslow (1987) argues that the HoN is not a 'fixed order', he proposes that for 'most people' motivations will initially focus on the most basic levels of need and once satisfied, the person will shift focus (consciously or unconsciously) to needs at higher levels. He noted exceptions to this, for example the 'starving artist in the garret' who is so transfixed by expressing their talent they overlook needs for adequate nutrition or sleep, and where a person gives up their job to save their self-respect but as a consequence loses income putting themself at risk of hunger, or losing their shelter. In this way, Maslow acknowledges that, in terms of 'a list', the HoN will be context dependent. The 'needs' are interrelated and arguably equally important for the wellbeing (or QoL) of the individual.

Early models of QoL have been partly informed by Maslow's HoN, but have not been based on this theory directly (e.g. Solomon, Bouchouchi, Denisov, Hankiss, Mallmann and Milbrath, 1980, p223-33). It 
is also possible to identify synergies between QoL research and Maslow's work, in selection of 'variables' included in a National Quality of Life Index (Diener, 1995, p110), and more recently policy initiatives on rural 'QoL' (Brauer and Dymitrow, 2014). Researchers have also investigated development of a QoL model based directly on Maslow's HoN using statistical modelling (Kravetz, 2014). The modelling assumed the HoN has a strict hierarchical structure (disputed here), and applied 'facet theory' to investigate items generated to represent levels of the HoN. The analysis produced a structure with some similarity to, but ultimately inconsistent with Maslow's HoN (Kravetz, Florian and Wright, 1985; Kravetz and Katz, 1997 cited in Kravetz, 2014). Maslow's HoN $(1970,1987)$ has therefore been influential in QoL model development, but its hierarchical structure has not been supported. Nevertheless, it arguably offers a comprehensive, theoretically driven structure through which to investigate QoL for any individual.

\section{QoL and Sen's Capability Approach (1985)}

The work of Sen and colleagues on the Capability Approach (CA) (Sen, 1985) has been another major contribution in the QoL field. What drives the approach is assessment of wellbeing (or QoL), and judgments about equality or justice, or the extent of development of communities or countries towards acceptable QoL for different populations. Its primary focus is on the effective opportunities people have to lead a life they value. To this end, CA is more concerned with the social and environmental conditions that facilitate wellbeing, than with individual experience.

The core concepts underlying the approach include 'Functions' and 'Capabilities'. 'Functions' are described as 'beings and doings' and relate to the status of individuals, where attributes such a person 'being' well-fed and literate is held to demonstrate they are in a good state 'functionally' in these respects. 'Capabilities' are described as real opportunities, and 'freedoms' (which relate to a person's autonomy in engaging with such opportunities) to 'realise functionings' (Sen, 1985, 2004). That is, to have access to resources (opportunity) and to be unfettered in those actions required (have freedom) to 'become' well fed or literate. These capabilities and freedoms, then, relate to provision of a 'good environment' for attainment of functionings. This resonates with Maslow's position as he noted, ' $a$ 
good environment (in theory) is one that offers all necessary raw materials and then gets out of the way ... to let the [(average) person] utter [their] wishes and demands and make [their]choices..." (Maslow, 1987, p120). They are the key contextual factors providing a person an opportunity to achieve a valued QoL (Robeyns, 2006).

Sen (1992, 1999, 2009 cited in Dang, 2014) uses the term 'conversion factors' to denote how 'commodities or resources' (raw materials) are mediated to provide individuals with the capability to achieve functionings (opportunities to fulfil needs) of one sort or another. Conversion factors comprise three categories - personal (physical condition, age, gender); social (institutions, cultural or social norms); and environmental (climate, pollution and public facilities). Conversion of available resources into wellbeing is therefore seen as dependent on individual, social and environmental features. 'Wellbeing' is regarded as 'an assessment of the particular achievements of the person - the kind of 'being he or she succeeds in having"' (Sen 1985a and b in Dang, 2014). In this context, 'agency freedom' comprises 'one's freedom to bring about the achievements one values and which one attempts to produce' (Sen, 1988), that is the freedom of individuals to 'decide' to act. This contrasts with 'freedom from societal constraints' upon a person that prevent them from acting on their choices.

Sen, however, is unwilling to generate a list of capabilities (Sen, 2004). He suggests that making a list of important capabilities is easy, but of limited use because they would be purely theoretical. He proposes any listing should arise from social discussion and public participation on decisions about potential attributes. He contends any list should be responsive to public opinion, and social or developmental change. Lists may be devised for specific purposes but there should be no 'definitive' list.

However, Sen (2004) notes the usefulness of Naussbaum's listing in relation to setting out minimal requirements to tackle deprivation within society. Nussbaum (2003) argues that her proposed 10 Central Human Capabilities list (Life; Bodily Health; Bodily integrity; Senses, imagination and thought; Emotions; Practical reason; Affiliation; Other species (to have relationship with); Play; Control over one's environment) is open and flexible, and notes that it has been revised several times and has broad crosscultural consensus. Similarly, Sen himself participated in development of the 'Human Development 
Index' for the United Nations Development Programme (UNDP), which specifies minimal requirements for QoL, calculable from available statistics, that would be more informative than use of nations' Gross National Product (GNP) or Gross Domestic Product (GDP) (Sen, 2004). The important point to note here is that this list was created within a particular context, for a particular reason.

The CA functionings identified by Sen (1985) and Nussbaum's Central Human Capabilities (2003) appear to have synergy with the earlier work by Maslow (1987) in terms of 'personal conversion factors', and to also demonstrate synergies to some extent between 'agency freedom' and the work on SelfDetermination Theory by Deci and Ryan (1985) discussed below. However, this theory is of particular relevance in signalling the importance of contextual resources - human and non-human, material and immaterial - that arguably impact QoL.

\section{QoL and Self-Determination}

Self-determination is a concept underlying aspects of choice and control over one's life, as briefly discussed above in relation to the place of the person within a model of QoL. It is of particular importance to people with ID who historically have had decision making opportunities removed, or considerably reduced, compared to the general population. However, it is not only about 'choice' but aspiration and personal goal setting. The idea that valued acts are those of inherent interest to individuals, and the importance of having freedom to pursue such interests evident in CA, are captured within Self Determination Theory (Ryan and Deci, 2000). Ryan and Deci (2000) distinguish between individuals' motivations to act that arise from their own interests and those occasioned by external pressures. They suggest different types of motivation have specific consequences for learning, performance, personal experience and wellbeing (p69).

'Intrinsic motivation' prompts individuals to seek out novelty and explore; to be inquisitive, curious and playful; and incline towards knowledge acquisition and skill mastery. These types of activities have 'inherent' value for the person because they are driven by their own interests. Ryan and Deci (2000) suggest that such pursuits represent the principle source of enjoyment and vitality throughout life. This 
notion of inherent curiosity within the human species is also ascribed to by Maslow (1987) who explored evidence for our desire to understand, systematize, organize, analyse, look for relations and meanings, and construct a system of values. This propensity to explore, investigate and learn may be argued responsible in large part for individuals' early but also ongoing personal and social development.

In this regard, learning based on individual interest has been proposed to be most 'effective' and satisfying, such that some independent schools and learning programmes have adopted this as a guiding principle (eg Summerhill schools, undated; Montessori approach, undated). Within most societies, however, some scheme of formal education is imposed in an effort to ensure individuals, and ultimately the wider population, have a least a minimum but also wide ranging levels of knowledge and skill. While these are personally useful, they also contribute to local and national agendas in relation to the wellbeing of communities and ambitions of nations. In regard to enhancing the QoL of people with ID, it underlines the importance of establishing personal interests and aspirations and facilitating pursuit of these goals.

'Extrinsic motivation', then, is described as imposed by others and requires the person to exhibit particular behaviours, for example to undertake particular forms of learning in the classroom, or tasks for an employer. Deci and Ryan (1985) propose that such imposition prompts a range of responses by the person from 'amotivation' (unwillingness to comply), and passive compliance, to active personal commitment. They suggest that the type of response given is dependent on the extent to which the person 'internalises' (accepts the premise for) the required act or behaviour. When the requirement is fully accepted (internalised) it is integrated into their 'world view' (they 'believe' in it). Consequently, the person pursues the activity/behaviour 'as if' it were intrinsically motivated, that is, as if they had decided on it themself.

Extrinsic motivators therefore interact with the 'autonomy' of the individual to determine their subjective experience and actions. A person may concede that compliance with an external demand aids them in pursuing an aspiration and so comply because it matches that ultimate goal. Another 
person may only comply due to social pressure to conform. Both these individuals complete the behaviour/activity but in the former case there is a 'sense' of choice (autonomy).

Ryan and Deci (2000) go on to suggest 'competence', 'autonomy' and 'relatedness' are three basic human needs. They suggest, for example, that extrinsically imposed acts are more likely to be accepted (internalised) if the person experiences a sense of 'competence' in completing the act. The task therefore provides a 'reward' of achievement even if it was not of interest in of itself. This may allow a person to grow in regard to their self-esteem; satisfying a 'need' to feel competent. Autonomy relates to choice and control of life circumstances, such that 'autonomy supporting' approaches to teaching, for example, are thought to promote individual initiative and effective learning. Ryan and Deci (2000) also contend that extrinsic motivations are more acceptable if prompted by 'others' who are valued by the person. That is, the demand emanates from someone they feel (or want to feel) 'related' to, or who represent a group they identity with (i.e. they experience 'communality'). If the context in which the behaviour is imposed allows the person to feel competent, autonomous (that there is active choice in compliance) and 'related' (part of a valued group - communality) they are likely to see the act as congruent with their own goals.

Ryan and Deci (2000) suggest that, where it is possible to satisfy competence, autonomy and relatedness needs (whether intrinsically or extrinsically motivated), the person will experience personal wellbeing, or health. Conversely they suggest that deprivation will result in ill health. This theory therefore stresses the importance of self-determination (choices) and within this freedom to act (control), along with achievement (esteem) and sense of group identity (culture) in achieving a 'good' QoL. It suggests the goals pursued should be one's own, or congruent with our ambitions, insofar as this is possible.

Maslow (1987) proposed that a single 'act' may be prompted by multiple motivations from across the spectrum of needs defined within his HoN. He also suggested that the act of fulfilling a need may become valued in itself through learning and change. For example, he states that the athletic ability 
required to hunt and capture food, initially focused on satisfying nutritional needs, may acquire a value of its own enhancing the proficient hunter's need for 'self actualisation' by enabling them to use their talent for athleticism. Foreshadowing Ryan and Deci's point in relation to deprivation of competence, autonomy and relatedness, Maslow (1987) suggested that frustration of attempts to fulfil a perceived important need may have a negative impact on the individual's physical or mental health.

The literature presented thus far outlines the complex interplay, not just of the needs of individuals and competing externally imposed and internally sought goals, but also the intricate web of contextual resources, rights, opportunities and cultural influences that may enhance or frustrate achievement of personally valued QoL. While Sen (1985) and Nussbaum (2003) have practiced some caution in determining the contextual/resource level 'list' of needs required for a 'good' life, ID researchers have come some way in outlining a number of important, apparently stable and reasonable 'domains' through which to attempt measurement of QoL for people with ID, and arguably for any person.

\section{QoL domains identified through Intellectual Disabilities Research}

Researchers in the field of intellectual disabilities have highlighted the multi-dimensional nature of QoL and explored the parameters of these dimensions (e.g. Emerson 1985: Felce and Perry, 1995; Renwick and Brown, 1996; Cummins, 1996; Wehmeyer and Schwartz, 1998; Schalock and Verdugo, 2002;

Bonham, Basehart, Schalock, Marchand, et al, 2004; Scott, Foley, Bourke, Leonard and Girdler, 2013). Importantly, cross-cultural work on the indicators (and/or domains) of QoL (Schalock, Verdugo, Jenaro, Wang, Wehmeyer, Jiancheng and Lachapelle, 2005) has investigated their 'universally shared' (individual) and 'culturally relevant' (contextual) dimensions. This duality resonates with Sen's (1985) conceptualisation of QoL based on 'functionings' and 'capabilities', where functionings are within the purview of individuals, whereas capabilities relate to the environmental context and whether, or to what extent, this facilitates individual efforts/growth towards a valued QoL. Based on previous work in the field (Schalock and Verdugo, 2002), well established domains of 'core QoL' were investigated across five countries (Spain, Latin-America, USA, Canada, and China). This study confirmed universal aspects of the eight domain structure of QoL proposed (Schalock et al 2005). The findings in relation to culturally 
determined aspects were more equivocal with ratings of some items within domains varying with cultural setting. However, the findings did not dispute the overarching domains. Such findings appear congruent with Maslow and Sen's propositions that while individuals will have the same underlying needs, their context, or culture, will moderate how these are responded to. It also supports the notion of a need for flexibility in response to individuals' circumstances, in use of models of QoL.

\section{Theoretical framework of the Quality of life Model}

The 'domains' of QoL emerging from the ID literature discussed above (Cummins, 1996; Schalock and Verdugo, 2002; Schalock et al 2005), embody important aspects of a person's lived experience, that are flexible enough to encompass dimensions proposed in earlier QoL research, such as those of Renwick and Brown (1985; 1996). These are: rights, social inclusion, self-determination, physical well-being, personal development, material well-being, interpersonal relations, and emotional well-being.

Schalock and Verdugo's (2002) eight QoL domains listed above, can be viewed as elements within which (in Maslow's terms) 'needs' exist. If and when these needs are fulfilled, it is reasonable to suggest a consequent, commensurate improvement in QoL for the individual may be expected to follow. However, while the eight domains indicate important aspects of life, they do not in themselves describe an associated concept of QoL. Providing a conceptual framework based on Maslow's HoN (1987) influenced by Sen's CA (1986) and able to take Schalock and Verdugo's (2002) domains into account, appears helpful in this regard. That is, the HoN provides facets of QoL that are arguably fundamental to a comprehensive, holistic conceptualisation of its nature into which contextual features may be accommodated, and the place of the person recognised.

In Table 1, domains identified by key researchers in the ID field are mapped to Maslow's HoN. Here 'generic' domain names commonly used in ID QoL research are provided and have been used to subsume other labels that are strongly related to the generic term. 
Table 1: Domains of Quality of Life identified in ID research mapped to Maslow's Hierarchy of Need

\begin{tabular}{|c|c|c|c|c|c|c|c|c|c|c|c|c|}
\hline $\begin{array}{l}\text { ID QoL } \\
\text { Domains* }\end{array}$ & 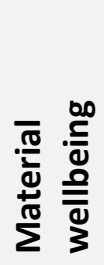 &  & 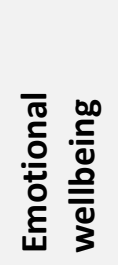 & 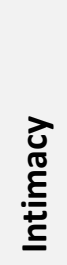 & 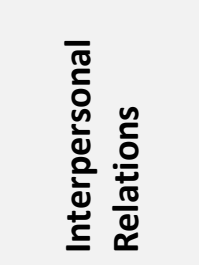 & 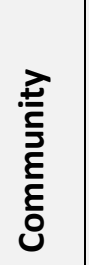 & 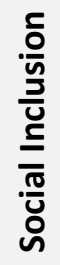 & 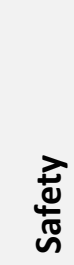 & 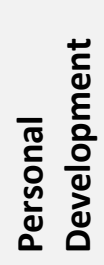 & 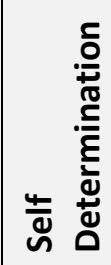 & 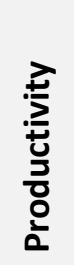 & $\frac{n}{\frac{n}{00}}$ \\
\hline $\begin{array}{l}\text { Schalock et } \\
\text { al, } 2005\end{array}$ & $\checkmark$ & $\checkmark$ & $\checkmark$ & & $\checkmark$ & & $\checkmark$ & & $\checkmark$ & $\checkmark$ & & $\checkmark$ \\
\hline $\begin{array}{l}\text { Bonham et } \\
\text { al } 2004\end{array}$ & $\checkmark$ & $\checkmark$ & $\checkmark$ & & $\checkmark$ & & $\checkmark$ & & $\checkmark$ & $\checkmark$ & & $\checkmark$ \\
\hline $\begin{array}{l}\text { Cummins } \\
1996\end{array}$ & $\checkmark$ & $\checkmark$ & $\checkmark$ & $\checkmark$ & & $\checkmark$ & & $\checkmark$ & & & $\checkmark$ & \\
\hline $\begin{array}{l}\text { Renwick } \\
\text { and Brown, } \\
1996\end{array}$ & & \multicolumn{2}{|c|}{$\begin{array}{c}\checkmark \\
\text { 'Being' }\end{array}$} & \multicolumn{5}{|c|}{$\begin{array}{c}\checkmark \\
\text { 'Belonging' }\end{array}$} & \multirow{2}{*}{\multicolumn{3}{|c|}{\begin{tabular}{c|c}
$\checkmark$ & \\
'Becoming' & \\
$\checkmark$ \\
'Development and \\
activity'
\end{tabular}}} & \\
\hline $\begin{array}{l}\text { Felce and } \\
\text { Perry, } 1995\end{array}$ & $\checkmark$ & $\checkmark$ & $\checkmark$ & & 'Social v & Ilbein & & & & & & \\
\hline $\begin{array}{l}\text { Maslow, } \\
1970 ; 1987\end{array}$ & & $\checkmark$ & \multicolumn{2}{|c|}{$\checkmark$} & $\checkmark$ & \multicolumn{2}{|c|}{$\checkmark$} & $\checkmark$ & \multicolumn{2}{|c|}{$\checkmark$} & & \\
\hline $\begin{array}{r}\text { Hierarchy } \\
\text { of needs }\end{array}$ & & $\begin{array}{l}\frac{\pi}{0} \\
\frac{0}{00} \\
\frac{0}{n} \\
\frac{1}{2}\end{array}$ & \multicolumn{2}{|c|}{ 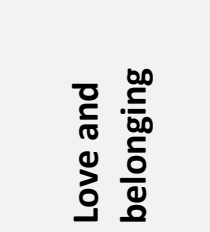 } & 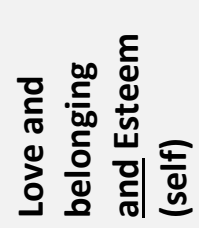 & \multicolumn{2}{|c|}{ ع } & 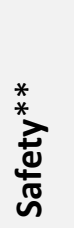 & \multicolumn{2}{|c|}{ 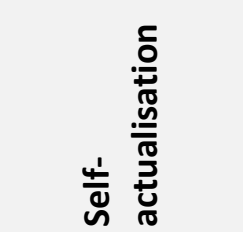 } & & \\
\hline
\end{tabular}

* Where cells straddle several columns the named 'group domain' includes these separate domains

** 'Safety' followed 'Physiological' need in Maslow's HoN - it has been displaced above to facilitate mapping.

An examination of the indicators representing particular domains, suggests that these can, for the most part, be represented within Maslow's HoN. Table 1 shows Schalock et al's (2005) domain of 'Rights', Cummins' (1996) domain of 'Productivity' (related to activity, learning and employment), and the jointly identified domain of 'Material Wellbeing' (related to housing, finance and possessions: Cummins, 1996; Schalock et al 2005) are not represented in the HoN, arguably because these reflect contextual and not individual aspects important for QoL/wellbeing. However, Maslow includes such notions in what he terms the 'preconditions' necessary to fulfil needs (Maslow, 1987, p.22). Sen (1992) and Nussbaum's (2003) work on CA, recognises that an individual's 'functionings' require concomitant 'capabilities', including rights, productivity and other elements of material wellbeing, if they are to be achieved. That is, that contextual resources, freedoms and opportunities should be available to individuals, to facilitate achievement of a functional status representing a personally satisfying, or 'good' life. The contextual dimension, vital in supporting QoL, was addressed comprehensively in the model proposed here. 
The broad structural coherence of the domains identified in the above literature, have been rationalised into a framework outlining four 'facets' of QoL adapted from Maslow's HoN (1987), each of which has two aspects representing individual and contextual features. The facets are named Foundational wellbeing (Maslow - physiological and safety), Psychosocial wellbeing (Maslow - love and belonging), Status (Maslow - esteem), and Autonomy (Maslow - self-actualisation).

In this QoL model, each facet is conceived as fundamentally intertwined with every other (as visually represented in Figure 1). The framework is pluralistic. In a development from Maslow's original concept it recognises the 'exceptions' he identified, that challenged the notion of hierarchy (Maslow, 1987, p26-7), as an integral part of the model. This conceptualisation is essential as each facet is considered equally important and 'non-tradable' (Brown, Hatton and Emerson, 2013) as a determinant of QoL. See Figure 1.

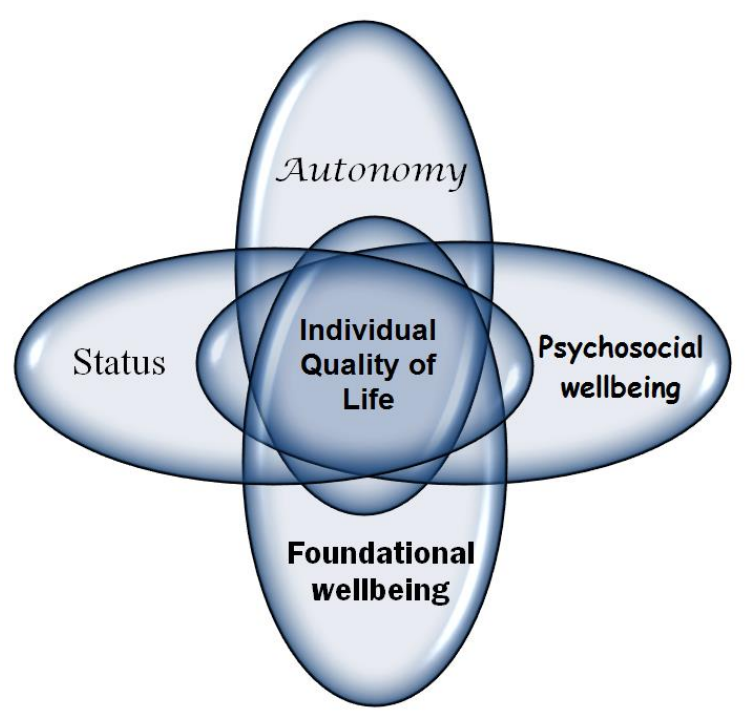

Figure 1: Quality of Life Experienced by Individuals

Each facet of the Model in figure 1 reflects a coherent cluster of 'needs' (Maslow, 1987) reflecting domains and indicators proposed by ID researchers (e.g. Schalock et al, 2005). The facets and their individual and contextual aspects are described in Table 2. The descriptors included are indicative and not absolute. In Sen's (2004) terms, furnishing an 'absolute' list of criteria is not feasible and possibly counterproductive. Indeed, Maslow observed that in the HoN level of detail is a function of the degree to which any dimension is focused upon. As the degree of 'magnification' is increased so a level of detail, formerly invisible, becomes apparent (Maslow, 1987, p8). A model of QoL must be flexible enough to be responsive to different purposes, contexts and individuals, while retaining clarity of concept at its core. This was the aim here. 
Table 2: Quality of Life Model - Facets, Aspects and Elements

\begin{tabular}{|c|c|c|}
\hline \multirow[b]{2}{*}{ 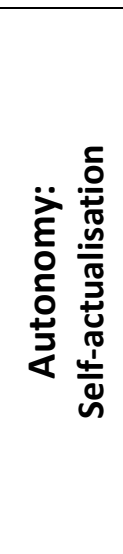 } & Individual Aspect & Contextual Aspect \\
\hline & $\begin{array}{l}\text { Aspiration / personal development } \\
\text { Self-actualisation } \\
\text { - Employing personal talents } \\
\text { - Following own interests } \\
\text { Self-realization } \\
\text { - Having self-awareness / self-knowledge } \\
\text { Self determination } \\
\text { - Pursuing own choices / goals / aspirations } \\
\text { Self-regulation } \\
\text { - Maintaining efforts to reach goals } \\
\text { Environmental 'ease' } \\
\text { - Gaining pleasure / comfort from one's surroundings }\end{array}$ & $\begin{array}{l}\text { Empowerment } \\
\text { Education/Learning } \\
\text { - Freedom to investigate / research } \\
\text { - Access to 'education' } \\
\text { Employment } \\
\text { - Access to fulfilling occupation } \\
\text { Personal Services } \\
\text { - Support to pursue aspirations }\end{array}$ \\
\hline
\end{tabular}

\begin{tabular}{|c|c|c|}
\hline & Individual Aspect & Contextual Aspect \\
\hline 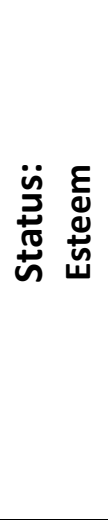 & $\begin{array}{l}\text { Self esteem } \\
\text { Stable positive evaluation of self / competence } \\
\text { Perceived high reputation / prestige } \\
\text { Self-respect } \\
\text { Perceived personal adequacy / competence } \\
\text { Self-worth / perceived usefulness in the world } \\
\text { Community Status } \\
\text { Accepted community member } \\
\text { Valued community member / prestige }\end{array}$ & $\begin{array}{l}\text { Rights/norms } \\
\text { Freedom to: } \\
\text { - Speak/act/ defend oneself } \\
\text { Access to: } \\
\text { - Justice / Fairness / Honesty } \\
\text { Social } \\
\text { Community facilities } \\
\text { - Provided for public good } \\
\text { Social groups } \\
\text { - Based on common pursuits } \\
\text { Action groups } \\
\text { - Based on common cause / mutual support }\end{array}$ \\
\hline
\end{tabular}

\begin{tabular}{|c|c|c|}
\hline & Individual Aspect & Contextual Aspect \\
\hline 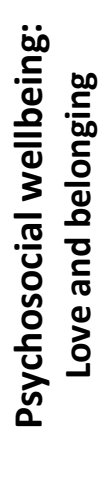 & $\begin{array}{l}\text { Communality } \\
\text { 'Roots' / cultural / ethnic / social group } \\
\text { Shared identity } \\
\text { Companionship } \\
\text { Shared life experience } \\
\text { Intimacy } \\
\text { Attachment [to caregiver(s) - child] } \\
\text { Partnership } \\
\text { Sexual relationship } \\
\text { Procreation }\end{array}$ & $\begin{array}{l}\text { Interpersonal Relationships } \\
\text { Community facilities / opportunities / freedoms for } \\
\text { social interaction } \\
\text { Positive (mutually beneficial) supportive interactions } \\
\text { with/in: } \\
\text { - Personally defined 'nuclear family' } \\
\text { - Extended family } \\
\text { - Friends / Acquaintances } \\
\text { - Neighbourhood } \\
\text { - Nation/state (recognised member vs outcast) }\end{array}$ \\
\hline
\end{tabular}

\begin{tabular}{|c|c|c|}
\hline & Individual Aspect & Contextual Aspect \\
\hline 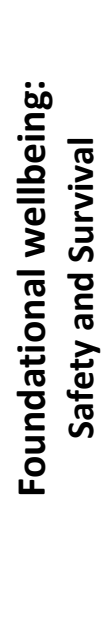 & $\begin{array}{l}\text { Physiological wellbeing } \\
\text { Nutrition } \\
\text { Rest } \\
\text { Hygiene } \\
\text { Activity } \\
\text { Safety wellbeing } \\
\text { Protection (from harm) } \\
\text { Predictability / dependability } \\
\text { Reserves (insure against unknown) } \\
\text { Familiar environments } \\
\text { Guidance / moral code (eg religious / spiritual } \\
\text { philosophy) }\end{array}$ & $\begin{array}{l}\text { Material wellbeing } \\
\text { Shelter } \\
\text { Food, water, other essential consumables } \\
\text { Facilities: cooking / hygiene rest/ travel } \\
\text { Financial } \\
\text { - Access to sufficient funds } \\
\text { - Opportunity to earn } \\
\text { Personal Safety and Wellbeing } \\
\text { Home } \\
\text { - Stable / Secure } \\
\text { Community } \\
\text { - Law and order } \\
\text { - Opportunities for activity / health support } \\
\text { Environment } \\
\text { - Benign }\end{array}$ \\
\hline
\end{tabular}


Table 2 describes the four facets of the model, and its individual and contextual aspects. 'Individual' aspects represent QoL in respect of the person to whom the model is applied. These aspects contain 'elements' representing a range of 'needs' of potential significance within that facet for the QoL of an individual. 'Potential' because the importance, or salience, of each element is likely to vary for any individual over time depending on their perceived and actual life circumstance. 'Contextual' aspects of each facet represent typical material and immaterial resources important in providing the conditions (opportunities, freedoms, and social and environmental 'conversion factors', Sen 1992, cited in Dang, 2014) to enable 'need' fulfilment.

Foundational wellbeing combines Maslow's (1987) 'Physiological' and 'Safety' HoN levels. The elements here include personal 'needs' and contextual resources necessary for functioning as a biological entity and address the critical 'need' to be safe, to feel comfortable that life is threat free. Both 'physical' and 'safety' needs are considered fundamental for a good QoL.

Psychosocial wellbeing concerns the personal connections we have to others in our milieu, that are important for mental health, and the conditions necessary to make and maintain such connections. Human beings are largely social in nature, we therefore seek relationships with others that occur at a number of levels. We seek Intimacy to satisfy our need for strong personal attachment with someone who will be our life and sexual partner, and with whom we seek to raise children; Companionship of others with whom to share life experiences; and Communality with those among whom we sense a shared identity. Successfully fulfilling these needs in a personally valued way is important for psychological wellbeing and a 'good' QoL.

Status comprises individual characteristics related to what Maslow termed 'higher needs' (1987) and relates to elements of 'esteem'. This involves a person's estimation of themself, and the esteem (and respect) they perceive, and attain from their local and wider communities. These elements are 
facilitated through freedoms and opportunities to access public institutions, and reflect extent of recognition of a person's rights and normative status (acceptance) within their community.

Autonomy is aligned with Maslow's 'higher need' of 'self-actualisation' (and within that aestheticism). 'Self-actualisation' is considered to be part of a wider group of needs relating to individuals' intrinsically motivated (self-directed) goals and aspirations. It is arguably dependent on fulfilling other needs, including the need for a person to be self-aware, to set their own goals, and to maintain efforts in reaching these goals. These goals and aspirations are underpinned by a context where freedoms, opportunities and support are available to pursue valued goals.

\section{Part 3 - Discussion}

\section{The nature of QoL}

The person within this QoL model is highly interconnected with their context, and not isolated from it. The nature of QoL is, therefore, characterised by 'self-society-place' interactions within and between each of the four proposed facets. 'Self' (the person), 'society' and 'place' represented within the model are briefly outlined below.

Self: is highly evident throughout the model as only the person may make authentic judgements about how they experience their QoL. So, what are the aspects of 'self' that impact this assessment? The literature demonstrated that a person's characteristics, such as genetic disposition and personality, values engrained through socialisation, and short lasting events and states such as mood, influence a person's evaluation of their QoL. The foundation of a person's QoL is represented as possession of optimal physical condition, and sense of/actual safety and security in life. Beyond this, individuals are inclined to seek out new experiences, investigate, and seek to attain new skills. A sense of wellbeing and personal satisfaction is gained when they determine their life course in this way (Maslow, 1987); Ryan and Deci, 2000). Possession of knowledge, skills and other attributes society values impacts their status. Self-respect (perceived competence in areas of personal importance - Ryan and Deci, 2000) and self-worth (perceived usefulness in the world) are jointly manifest in their level of self-esteem. Similarly, 
where a person gains esteem from their community, and they perceive they are accepted and well thought of (achieve 'relatedness' - Ryan and Deci, 2000) their psychological wellbeing is enhanced (Maslow, 1987). Here self-determination, especially pursuit of intrinsically motivating goals (Ryan and Deci, 2000) appears constituent to QoL. Renwick and Brown's CHP model (1996) supports this proposition arguing 'degree of control' moderates perceived QoL. Self-determination is considered at its peak where in pursuing their goals individuals, inspired by intrinsic interest, employ their own particular talents (self-actualisation - Maslow, 1987; 'autonomy' - Ryan and Deci, 2000).

Self-determination, therefore, underlies negotiation of this QoL model privileging the view of the person, though the necessity of concurrent objective assessments of Qol remains. This includes the freedom to make 'ill-advised' choices where this is clearly an informed decision (Edgerton, 1990). This description of the nature of 'self' outlines personal characteristics that impact achievement and evaluation of QoL. However QoL is not wholly determined by individual factors; contextual features are also key.

Society: is hugely influential on both the person and other contextual features of life, and so fundamental in defining the nature of QoL. The nature of 'Society', and how it impacts QoL, is therefore important as it offers explanations on how individual and contextual aspects of QoL may interact. Deleuze and Guattari (1980, cited in Dolwick, 2009) propose 'the social' is a combination of 'people, groups, things and ideas' that are interconnected such that, for example, the person and political states are not separate but as 'plugged in' to each other and continually evolving into something different. This suggests 'individual' and 'contextual' aspects of QoL are locked in interactions that can enable or hinder achievement, or progress towards goals that are aspired to.

'Society' is therefore conceptualised as comprising human individuals and non-human entities, including other species, material objects (produced or natural) and immaterial objects (such as laws, traditions, events), and characterised by interactions between persons, and persons and 'things'. Interactions with 'things' however, have been considered of a different order to human interaction because things do not have capacity to decide to act, or be 'motivated' to act. It was suggested that people 'act on' things, but 
not with, through or in response to them (Durkheim, 1938). In this QoL model, however, it is accepted that relationships are more complex than this suggests. For example, non-human animals do have the capacity to act, based on motivating factors of relevance to that animal (e.g. Mellor, 2016). Material objects, though they have no capacity to act based on motivating factors, have a physical reality that is subject to contextual factors that may render them changed and impact on persons, affecting their QoL. Immaterial objects, often created through actions of social groups, may be designed to impact on persons, to create order, engender bonding in social groupings, or provoke an emotional response in relation to aesthetics (e.g. music, spirituality). These objects embody a secondary representation of individual/group generated motivators and/or 'directives'. As such these non-human entities are considered to have the potential to be important contextual determinants of, or foci for a person's subjective evaluation (and objective assessment) of QoL. 'Self', therefore, is defined by individual physical and psychological characteristics, but also entirely enmeshed in 'the social'. However, both self and society are embedded within 'place' which plays a key role in shaping both.

Place: refers to elements of context relating to the physical environment, both natural and built and includes elements such as climate, pollution and public facilities (Sen 1992, 1999, 2009 cited in Dang, 2014). While environmental quality is partly determined by our activities that impact upon it, its activities impact on us, and so it is constituent to QoL. Within a defined geographical region the extremes of weather or geological movements, beyond the control of society, will affect all and run their course, impacting QoL. However, aspects of the built environment may differentially affect individuals due to society's response to population needs. A society's efforts in accommodating 'needs', such as provision of electricity for light, heat, work objects and entertainment, mean that most of its people may be enabled to live a comfortable life. However, where specific needs are overlooked, individuals are negatively impacted by elements of the built environment. Access, and other needs of people with disabilities have clearly been affected in this way; despite contemporary efforts in, for example, facilitating physical access to the built environment. While such impacts are socially determined, however, they occur outside direct social interaction in the context of 'place'. In this Model, therefore, 
individuals' QoL is considered to be impacted by the 'place' they are in, their 'social' contacts, and characteristics that define their 'self', which combine to facilitate or thwart experience of a 'good' QoL.

There is much that might be 'unpacked' from this model and the notions that underpin it. However it is important here to consider use of the model, and so key points arising from the conceptualisation and presentation above are briefly discussed below.

\section{Use of the Model}

The worth of any model of QoL is in doubt if it cannot be applied to help facilitate actions to promote and improve life circumstances. Hence the implications for use of this model are considered below. Here it has been argued that any assessment of QoL should be based on an understanding of its nature. Its nature is complex, and so theories underlying this model suggest a necessity for generic descriptors in holistic conceptualisation of QoL (Maslow, 1970, 1987 and Sen 1985); that specificity needs to be added in its application to ensure relevance to those circumstances evaluated. In using the model, it follows that the purpose must be clearly defined and related facets and elements delineated. However, investigation of QoL demands a pluralistic approach, which engages fully and equally with individual and contextual aspects of a defined circumstance of interest; but also accounts for influences of, and on facets of the model not under direct investigation. In mapping out and assessing the aspects and elements of a specified circumstance, an open-minded exploratory approach appears key in tapping the evident interrelationships between individual (self) and context (society - place). Here Latourian actornetwork theory (ANT) appears of some relevance (Latour, 2005). ANT is a complex and controversial theory based on ethnographic approaches to sociological theorising. However, Latour (2005 p131) also stated '[ANT] is a tool to help describe something, not what is being described.' It is in this sense of being a tool designed to capture any elements relevant to a situation of interest that has value here.

Latour (2005) proposed ANT derives insights using ethnomethodology, and allows governmental/social and personal elements to be accounted for within a unified analysis of a set of circumstances. An 'actornetwork' would inform investigation (assessment) of QoL by making connections between human and 
non-human entities ('actors'), related to a matter of 'concern', but importantly, make no a priori assumptions about what might be connected (Latour, 1996). In general these entities (humans, nonhuman species, material or immaterial objects) are thought of as transforming each other and being transformed when they connect. This idea of interactions having mutual consequences is appropriate to the QoL Model proposed. It has resonance with Michalos' (2014) point that the subjective evaluation of circumstances by a person influences the actions they take in response, which in turn impact not only the person (with ID) themself, but also others with whom they connect. While this point related to interpersonal interactions, in an ANT 'analysis' a record is made of the impacts of and on all entities playing a role, including the non-human (Latour 2005). Depending on the circumstances explored, wide ranging elements may be shown to have important impacts on QoL, and must be accounted for (qualitatively and/or quantitatively) if a realistic account of the circumstance is to be derived.

The psychological literature on subjective wellbeing, and Jankey and Day's (1996) conclusion that individuals' life circumstances $(\mathrm{Q} o \mathrm{~L})$ are unique and likely to vary over time depending on what is important to the person, make similar arguments regarding the fluctuating nature of QoL. Their conclusions highlight the importance of flexibility in assessment, to account for enduring individual differences (temperament/disposition) and short term events arising from a person's mood, or wider context, that influence perception of QoL. Any assessment can only grasp a snapshot of the elements of QoL (actor-network) available to us as researchers (or service providers) at that moment. Accordingly, Latour (2005; and Harman, 2009) suggested an assessment should not take a 'once and for all' approach, because it is not an enduring representation. However, using a series of ANT assessments one could examine layers of that circumstance over time (Harman, 2009). It appears reasonable that comparison of temporally separate episodes of 'mapping' may provide insights on the influence of personal or contextual factors. This suggests that QoL is likely to be represented by a profile rather than a single 'score'. In supporting gains in QoL, this appears positive and potentially informative. Mapping an individual's evaluation of their needs and aspirations, the extent to which they are met, and connections to facilitating or obstacle creating contextual features implicated in supporting or thwarting life goals, 
could provide a clear mandate on which to seek to maintain or to improve/develop resources. However, it must be noted that it has been beyond the scope of this article to fully explore existing literature on issues implicated in application of overarching models to service applications.

The idea of embracing the evident complexity of QoL in pursuit of biopsychosocial goals is appealing because it suggests an opportunity to get closer to a 'real' evaluation of QoL. ANT resonates with the QoL conceptualisation here inasmuch as it characterises 'experience' as idiosyncratic; determined by contextual impacts on, the subjective evaluation of, and responses by the individual concerned. It allows that the facets and aspects of the QoL model are simultaneously and multiply 'active' in an individual's life. Having defined a purpose, taking a non-judgemental approach to what is included within an evaluation of QoL supports the pluralistic stance of the QoL model proposed here.

\section{What the QoL Model contributes}

The model proposed was conceptualised in the context of people in general and no group specifically. People with ID, or other disabilities or complex needs, are entitled to aspire to a QoL of the same order as any other person. Day and Jankey (1996) noted that early QoL models had different specifications because they were constructed for use in different and restricted circumstances. Here, following Renwick and Brown (1996), a comprehensive, holistic conceptualisation of QoL is proposed so that it may inform a range of uses. It is argued that realistic evaluation of QoL is dependent on an understanding of its nature. Formerly, social/psychological indicators approaches which focused on specific circumstances were dominant. These employed atheoretical 'concern' derived, social policy goal, or researcher designated indicators in investigation. In the literature reviewed, no underpinning concept of the nature of QoL was identified and aspirational elements appeared missing. However, engagement with the cross-discipline QoL literature clearly demonstrates that the concept is vast and defies 'definitive' specification; those who attempt the task can easily become lost in a universe of detail. The contribution here is, necessarily, a view of the concept at some distance, allowing its shape to be outlined so the emerging QoL 'atlas' may provide a useful guide. 
This QoL model adopts Maslow's theories of motivation and personality, embodied in his HoN (1970, 1987), and Sen's theories on the capability approach (1985), in which 'good' QoL is seen as dependent on achievement of 'capabilities' (opportunities) to realise 'functionings' (needs). Recognition of the person in the model was established through emphasis on self-society-place interactions, and the importance of self-determination (including choice and control) which may promote, not only improvements in QoL, but gains in psychological wellbeing.

It is acknowledged that any model is only of value if it can inform actions to improve the lives of individuals or groups - that is, to underpin social, educational or clinical policies, interventions or services. It seems reasonable to suggest that a first step in such action must be to assess current status and gain an understanding of the person, their subjective and objective circumstances, experiences, preferences, and aspirations. Critically, the goal of QoL evaluation should be valued by the person concerned (Amando, Stancliffe, McCarron \& McCallion, 2013). Particular challenges faced by any individual will be constituent of, and impact the outcome of QoL investigation. A QoL assessment, through identification of contextual resources and personal strengths, should then arguably enable the person to strive towards the QoL they aspire to.

As a guide (or 'atlas'), the model aims to support researchers and service providers in their decisions as to what is relevant to a QoL assessment. It aims to overcome some of the criticisms of models based on researcher defined domains by proposing an exploratory approach to assessment of QoL, reflecting the dynamic nature of the phenomenon. Here, an ANT type approach (Latour, 2005) appears appropriate to capture this dynamism by mapping the impacts of identified elements connected with the circumstances assessed. In this way, the person and the wider circumstances themselves ultimately delineate what is relevant to that QoL evaluation. Such assessments have potential to uncover what a person perceives, and objective evidence reveals their QoL is like. Moreover, it may also provide evidence to explain those perceptions and revelations, and inform actions to address obstacles to improved QoL. 


\section{Limitations}

It has been beyond the scope of this article to fully explore the implications of the Model for application in practice. It is also acknowledged that, while a cross-disciplinary approach was adopted, due to limitations of space 'bio' features of 'self' and wider environmental features of 'place', in particular, are relatively under-defined. However, in outlining the proposed nature, and a potential approach to assessment of QoL, a step towards addressing such matters has been taken.

In terms of national assessments, where a 'finger to the wind' outcome is all that is required and so an exploratory approach is not appropriate, it is suggested that consideration of 'what' data is collected can still be informed by this model of the nature QoL. Further, through ongoing research using the model as a guide, a body of evidence may be accumulated in relation to particular populations, or social circumstances, to inform policy and practice.

\section{Conclusion}

This model was created to reflect psychological, social and econometric theory on the nature of QoL. It is proposed that recognition of the nature of this concept is necessary if we are to realistically attempt to measure the QoL of individuals. An informed measurement of QoL is, reasonably, fundamental to evidence based courses of action seeking to improve the lives of specific populations. Interventions, services and support developed on the basis of such an understanding and assessment, may arguably be more effective in achieving their objective. However, the model outlined here is the beginning of a process moving towards such a goal, and not the end of it. 


\section{References}

Amado, A.N., Stancliffe, R.J., McCarron, M., and McCallion, P. (2013). Social Inclusion and Community Participation of Individuals with Intellectual /Developmental Disabilities. Intellectual and Developmental Disabilities, 51(5), 360-75.

Andrews, F.M., and Withey, S.B. (1976). Social Indicators of Well-being: Americans' Perceptions of Life Quality. New York: Plenum Press.

Antonovsky, A. (1987) Unraveling the mystery of health. San Francisco, Jossey-Bass.

Bach, M. and Rioux, M.H. (1996). Social well-being: A framework for Quality of Life research. In, Renwick, R., Brown, I. \& Nagler, M. (Eds) Quality of life in health promotion and rehabilitation: conceptual approaches, issues and applications. Thousand Oaks, Sage Publications. P63-74.

Bonham, G.S., Baseheart, S., Schalock, R.L., Marchland, C.B., Kirchner, N. and Rumenap, J.M. (2004). Consumer-based quality of life assessment: The Maryland Ask Me! Project. Mental Retardation, 42(5), 338-355.

Brauer, R., and Dymitrow, M. (2014). Quality of life in rural areas: A topic for the rural development policy? Bulletin of Geography. Socio-economic Series, 25, 25-54.

Brown, I., Hatton, C. and Emerson, E. (2013). Quality of life indicators for individuals with intellectual disabilities: Extending Current Practice. Intellectual and Development Disabilities, 51(5), 316-32. Bryman, A. (2012). Social Research Methods (4 ${ }^{\text {th }}$ edition). Oxford University Press. Campbell, A., Converse, P.E. and Rodgers, W.L. (1976). The quality of American life: Perceptions, evaluations and satisfactions. New York, Russell Sage Foundation.

Cummins, R. (1996). The domains of life satisfaction: an attempt to order chaos. Social Indicators Research, 38(3), 303-328.

Cummins, R. (2005). Moving from the quality of life concept to a theory. Journal of Intellectual Disability Research, 49(10), 699-706.

Dang, A. (2014). Amartya Sen's Capability Approach: A framework for well-being evaluation and policy analysis? Review of Social Economy, 72(4), 460-484. 
Day, H. and Jankey, S.G. (1996). Lessons from literature: Towards a holistic model of Quality of Life. In Renwick, R., Brown, I. and Nagler, M. (Eds) Quality of life in health promotion and rehabilitation: conceptual approaches, issues and applications. Thousand Oaks, Sage Publications. 39-50.

Deci, E.L. and Ryan, R.M. (1985). Intrinsic motivation and self-determination in human behaviour. New York: Plenum.

Diener, E. (1984). Subjective well-being. Psychological Bulletin, 95, 542-575.

Diener, E. (1995). A value based index for measuring national quality of life. Social Indicators Research, $36(2), 107-127$.

Diener, E., Suh, E.M., Lucas, R.E., and Smith, H.L. (1999). Subjective well-being: Three decades of progress. Psychological Bulletin, 125, 276-302.

Dolwick, J. (2009). 'The social' and beyond: Introducing actor-network theory. Journal of Maritime Archaeology, 4(1), 21-49.

Durkheim, E. (1938). The rules of sociological method. New York, Free Press of Glencoe.

Easterlin, E. (2005). Building a better theory of well-being. In L. Bruni and P. Porta (Eds) Economics and happiness: Framing the analysis. Oxford, Oxford University Press.

Edgerton, R.B. (1990). Quality of Life from a longitudinal research perspective. In, Schalock, R.L. (Ed) Quality of Life: Perspectives and Issues. Washington, American Association on Mental Retardation. 149160

Emerson, E. (1985). Evaluating the impact of deinstitutionalisation on the lives of mentally retarded people. American Journal of Mental Deficiency, 90, 277-288.

Equality Act 2010. United Kingdom Government. London, The Stationary Office. Available from http://www.legislation.gov.uk/ukpga/2010/15/contents

Eysenck, M.W. (2000). Psychology: A student's handbook. Hove, Psychology Press Ltd, Taylor \& Francis Group.

Flanagan, J.C. (1982). Measurement of quality of life: Current state of the art. Archives of Physical Medicine and Rehabilitation, 63, 56-59. 
Felce, D. and Perry, J. (1995). Quality of life: its definition and measurement. Research in Developmental Disabilities, 16(1), 51-74.

Goode, D.A. (1990). Thinking about and discussing Quality of Life. In Schalock, R.L. (Ed) Quality of Life: Perspectives and Issues. Washington, American Association on Mental Retardation 41-57.

Harman, G. (2009). Prince of Networks: Bruno Latour and Metaphysics. Melbourne, re.press.

Headey, B. (2014). Set-point theory. In A.C. Michalos (Ed) The Encyclopedia of Quality of Life and Wellbeing Research. Netherlands, Springer. 5855-5857

Kiuranov, C. (1980). An integral indicator of the quality of work and quality of life. In Szalai, A and Andrews, F.M. (Eds) The Quality of Life: Comparative Studies. London, Sage Publications.

Kravetz, S. (2014). Quality of Life, Radex Model. In, A.C. Michalos (Ed) The Encyclopedia of Quality of Life and Wellbeing Research. Springer Netherlands. 5298-5305.

Langeland, E. (2014). Sense of Coherence. In, A.C. Michalos (Ed) The Encyclopedia of Quality of Life and Wellbeing Research. Springer Netherlands. 5831-5833.

Latour, B. (2005). Reassembling the social: an introduction to actor-network theory. Oxford, Oxford University Press.

Latour, B. (1996). On actor-network theory: A few clarifications. Soziale Welt, 47, 369-381. Available from http://www.jstor.org/stable/40878163 [Accessed 01.04.2016]

Lykken, D. and Tellegen, A. (1996). Happiness is a stochastic phenomenon. Psychological Science. 7, 186189.

Maslow, A.H. (1987). Motivation and Personality. $3^{\text {rd }}$ Edition. New York: Harper \& Row, Publishers, Inc. Maslow, A.H. (1970). Motivation and Personality. $2^{\text {nd }}$ Edition. New York: Harper \& Row, Publishers, Inc. Mental Capacity Act 2005 - United Kingdom Government. London, The Stationary Office. Available from http://www.legislation.gov.uk/ukpga/2005/9/contents

Mellor, D.J. (2016). Updating animal welfare thinking: Moving beyond the 'five freedoms' towards 'a life worth living'. Animals, 6(3) 21. doi 10.3390/ani6030021.

Michalos, A.C. (2014). Quality of Life, Two-Variable Theory. In A.C. Michalos (Ed) The Encyclopedia of Quality of Life and Wellbeing Research. Netherlands, Springer. 
Montessori. (undated). Reach - An introduction to the Motessori movement across the UK. Available from: http://www.montessori.org.uk/ data/assets/pdf file/0004/99022/Reach feb 2012.pdf

Musek, J. (2007). A general factor of personality: Evidence for the Big One in the five factor model. Journal for Research in Personality. 41, 1213-1233.

Nussbaum, M. (2003). Capabilities as fundamental entitlements: Sen and social justice. Feminist Economics, 9(2-3), 33-59.

Ormel, J. (1983). Neuroticism and well-being inventories: Measuring traits or states? Psychological Medicine, 72, 165-176.

Renwick, R., Brown, I. and Nagler, M. (Eds) (1996). Quality of life in health promotion and rehabilitation: conceptual approaches, issues and applications. Thousand Oaks, Sage Publications.

Renwick, R. and Brown, I. (1996). The Centre for Health Promotion's conceptual approach to quality of life: Being, Belonging, and Becoming. In Renwick, R., Brown, I. and Nagler, M. (Eds) Quality of life in health promotion and rehabilitation: conceptual approaches, issues and applications. Thousand Oaks, Sage Publications. 75-86.

Robeyns, I. (2006). The capability approach in practice. Journal of Political Philosophy, 14(3), 351-376. Ryan, R.M., and Deci, E.L. (2000). Self-determination theory and the facilitation of intrinsic motivation, social development, and well-being. The American Psychologist, 55(1), 68-78.

Ryan, R.M., Stiller, J., and Lynch, J.H. (1994). Representations of relationships to teachers, parents, and friends as predictors of academic motivation and self-esteem. Journal of Early Adolescence, 14, 226-249. Schalock, R.L. (Ed) (1990). Quality of Life: Perspectives and Issues. Washington, American Association on Mental Retardation.

Schalock, R.L. (1990). Attempts to conceptualize and measure quality of life. In, Schalock, R.L. (Ed) Quality of Life: Perspectives and Issues. Washington, American Association on Mental Retardation. 141148.

Schalock, R.L. and Thornton, C.V. (1988). Program evaluation: A field guide for administrators. New York, Plenum Publishing Company. 
Schalock, R.L., and Verdugo, M.A. (2002). Handbook on quality of life for human service practitioners. Washington, DC: American Association on Mental Retardation.

Schalock, R.L., Verdugo, M.A., Jenaro, C., Wang, M., Wehmeyer, M., Jiancheng, X., and Lachapelle, Y. (2005). Cross-cultural study of quality of life indicators. American Journal of Mental Retardation, 110(4), 298-311.

Schnittker, J. (2008). Happiness and success: Genes, families, and the psychological effects of socioeconomic position and social support. The American Journal of Sociology, 114(Suppl. 1), S233S259.

Scott, M., Foley, K., Bourke, J., Leonard, H., and Girdler, S. (2013). "I have a good life": the meaning of well-being from the perspective of young adults with Down syndrome. Disability and Rehabilitation, 36(15), 1-9.

Sen, A.K. (1985). Commodities and Capabilities. Amsterdam: North-Holland.

Sen, A. (1988). Freedom of choice: Concept and content. European Economic Review, 32(2), 269-294. Sen, A. (2004). Capabilities, lists, and public reason: Continuing the conversation. Feminist Economics, 10(3), 77-80.

Solomon, E.S., Bouchouchi, N., Denisov, V., Hankiss, E., Mallmann, C.A. and Milbrath, L.W. (1980). UNESCO's Policy-relevant quality of life research program. In, Szalai, A. and Andrews, F.M. (Eds) The Quality of Life: Comparative Studies. London, Sage Publications. 223-234.

Stones, M.J., Kozma,A., McNeil, J.K. and Worobtz, S. (2011). Subjective well-being in later life: Twenty years after Butterworth's monograph series on individual and population aging. Canadian Journal on Aging. 30(3), 467-477.

Stones, M. and Shye, S. (2014). Top-Down QOL Models. In, A.C. Michalos (Ed) The Encyclopedia of Quality of Life and Wellbeing Research. Netherlands, Springer.

Summerhill. (undated). About A.S. Neill's Summerhill. Retrieved from: http://www.summerhillschool.co.uk/about.php Wang, C., and Burris, M.A. (1997). Photovoice: concept, methodology, and use for participatory needs assessment. Health, Education and Behaviour, 24(3), 369-87. 
Wehmeyer, M., and Abery, B. (2013). Self-determination and choice. Intellectual and Developmental Disabilities, 51(5), 399-411.

Wehmeyer, M., and Schwartz, M. (1998). The relationship between self-determination and quality of life for adults with mental retardation. Education and Training in Mental Retardation and Developmental Disabilities, 33(1), 3-12.

Weiss, A., Bates, T.C. and Luciano, M. (2008). Happiness is a personal(ity) thing: The genetics of personality and well-being in a representative sample. Psychological Science. 19, 205-210.

Zautra, A. and Goodhart, D. (1979). Quality of life indicators: A review of the literature. Community Mental Health Review, 4(1), 2-10. 